\title{
Greenberg dysplasia
}

INSERM

\section{Source}

INSERM. (1999). Orphanet: an online rare disease and orphan drug data base. Greenberg dysplasia. ORPHA:1426

Greenberg dysplasia is a very rare lethal skeletal dysplasia characterized by fetal hydrops, short limbs and abnormal chondro-osseous calcification. The disease is characterized by early in utero lethality and affected fetuses are considered as nonviable. 